\title{
Optimization of Supercritical Carbon Dioxide Extraction of Eucommia ulmoides Seed Oil and Quality Evaluation of the Oil
}

\author{
Zhen-shan Zhang ${ }^{1 *}$, Yu-lan Liu ${ }^{1}$ and Li-ming Che ${ }^{2 *}$ \\ ${ }^{1}$ College of Food Science and Technology, Henan University of Technology, NO.100, Lianhua Street, Zhengzhou 45001, P.R.CHINA \\ ${ }^{2}$ Department of Chemical and Biochemical Engineering, Xiamen University, No.422, Siming South Road, Xiamen 361005, P.R.CHINA
}

\begin{abstract}
Supercritical carbon dioxide extraction $\left(\mathrm{SC}-\mathrm{CO}_{2}\right)$ technology was used to extract oil from Eucommia ulmoides seed. The optimum conditions and significant parameters in $\mathrm{SC}-\mathrm{CO}_{2}$ were obtained using response surface methodology (RSM). The qualities of the extracted oil were evaluated by physicochemical properties, fatty acid composition, vitamin $\mathbf{E}$ composition. It was found that the optimum extraction parameters were at pressure of $37 \mathrm{MPa}$, temperature of $40^{\circ} \mathrm{C}$, extraction time of 125 min and $\mathrm{CO}_{2}$ flow rate of $2.6 \mathrm{SL} / \mathrm{min}$. Pressure, temperature and time were identified as significant parameter effecting on extraction yield. The importance of evaluated parameters decreased in the order of pressure $>$ extraction time $>$ temperature $>\mathrm{CO}_{2}$ flow rate. $\mathrm{GC}$ analysis indicated that $E$. ulmoides seed oil contained about $61 \%$ of linolenic acid and its fatty acid composition was similar with that of flaxseed oil and perilla oil. The content and composition of vitamin $E$ was determined using HPLC. The $E$. ulmoides seed oil was rich in vitamin $E(190.72 \mathrm{mg} / 100 \mathrm{~g})$, the predominant vitamin $E$ isomers were $\gamma$ - tocopherol and $\delta$ tocopherol, which accounted for $\mathbf{7 0 . 8 7 \%}$ and $\mathbf{2 4 . 8 1 \%}$ of the total vitamin $\mathrm{E}$, respectively. The high yield and good physicochemical properties of extracted oil support the notion that $\mathrm{SC}-\mathrm{CO}_{2}$ technology is an effective technique for extracting oil from $E$. ulmoides seed.
\end{abstract}

Key words: supercritical carbon dioxide, Eucommia ulmoides seed oil, extraction optimization, fatty acid composition, vitamin E composition

\section{Introduction}

Eucommia ulmoides Oliv., which is also called "DuZhong" in Chinese, is a unique medicinal plant in China. The bark and leaf of $E$. ulmoides has been used as a traditional Chinese medicine for thousands of years. Now, $E$. ulmoides is mainly cultivated in China, Japan, Taiwan and Korea, etc. ${ }^{1)}$. In recent years, researches about E. ulmoides mainly focused on isolation of monomeric compounds, such as polysaccharide, chlorogenic acid, lignans, flavonoids and other trace elements from bark and leaves ${ }^{2-5}$, as well as the analysis of pharmacological functions of the bioactive substances ${ }^{6)}$. However, as one of the most important byproducts of $E$. ulmoides, the seed of $E$. ulmoides have not got enough attention. E. ulmoides seed contains about 10\%-15\% oil. After peeling, the oil content can increase to $30 \%-40 \%$.

It has been proven that supercritical carbon dioxide $\left(\mathrm{SC}-\mathrm{CO}_{2}\right)$ extraction is a very effective method to extract a variety of vegetable oils ${ }^{7-9)}$. Compared to conventional organic solvent, carbon dioxide as solvent have many advantages, such as non-toxic, non-flammable, easy to separate from the desired extract, no harmful solvent residues and no solvent disposal cost ${ }^{10)}$. Response surface methodology (RSM) which combines mathematics with statistics is often used to design experiments, build models, and evaluate the effect of factors. The main advantage of RSM is a small number of experimental trials needed to evaluate multiple parameters and their interaction. It has been successfully applied in various food processing operations ${ }^{11-14)}$. However, to the best of our knowledge, the effect of $\mathrm{SC}-\mathrm{CO}_{2}$ extraction parameters on yield of $E$. ulmoides seed oil have not been investigated and its physicochemical properties, especially vitamin E composition were also rarely reported.

The main objective of this study was to determine the effects of pressure, temperature, extraction time and $\mathrm{CO}_{2}$

\footnotetext{
*Correspondence to: Zhen-shan Zhang, College of Food Science and Technology, Henan University of Technology, NO.100, Lianhua Street, Zhengzhou 45001, P.R.CHINA. Li-ming Che, Department of Chemical and Biochemical Engineering, Xiamen University, No.422, Siming South Road, Xiamen 361005, P.R.CHINA.
}

E-mail: zzsan010@126.com (Z.Z.), Imc@xmu.edu.cn (L.C.)

Accepted October 5, 2017 (received for review July 8, 2017)

Journal of Oleo Science ISSN 1345-8957 print / ISSN 1347-3352 online

http://www.jstage.jst.go.jp/browse/jos/ http://mc.manusriptcentral.com/jjocs 
flow rate on yield of $E$. ulmoides seed oil, and to find the optimum processing conditions for $\mathrm{SC}-\mathrm{CO}_{2}$ extraction. In addition, the fatty acid composition, Vitamin E composition and physicochemical properties of E. ulmoides seed oil extracted at optimum conditions were evaluated.

\section{Materials and methods}

\subsection{Materials}

The E. ulmoides seed was purchased from the market in Zunyi city, Guizhou province, China. The seeds were cleaned and de-husked by hand, then stored in a self-sealing bag at $2-4^{\circ} \mathrm{C}$. The seeds were ground in a FW-100 domestic grinder (Beijing ever light medical equipment Co., LTD, Beijing, China) before use.

The carbon dioxide (99.9\%) was supplied by Yuanhua Gas Plant (Zhengzhou, China). Fatty acid methyl ester standards were purchased from Sigma Aldrich Corporation (Shanghai, China). Tocopherols $(\alpha-, \beta-, \gamma$ - and $\delta$-) and tocotrienols $(\alpha-, \beta-, \gamma$ - and $\delta$-) standards were purchased from Beijing Sunky Biological Technology Co., Ltd(Beijing, China). All chemicals used were of analytical or chromatographic grade.

\section{2 $\mathrm{SC}-\mathrm{CO}_{2}$ extraction}

The $\mathrm{SC}-\mathrm{CO}_{2}$ extraction of $E$. ulmoides seed oil was performed on a Helix system (Applied Separation, Allentown, PA, USA). The schematic flow diagram was shown in Fig. 1. Method were used as described by Kraujalis and Venskutonis ${ }^{15)}$ and with a slight modification. In each experiment, two hundred gram of $E$. ulmoides seed powder were put into a $1000 \mathrm{~mL}$ extraction vessel. The temperature of extraction vessel was controlled by the surrounding heating jacket. The flow rate of $\mathrm{CO}_{2}$ in the system was controlled manually by the micro-metering valve. The volume of $\mathrm{CO}_{2}$ was measured by a digital mass flow meter in standard liters per minute $(\mathrm{SL} / \mathrm{min})$ at a standard state $\left(P_{\mathrm{CO}_{2}}=100\right.$ $\left.\mathrm{kPa}, T_{\mathrm{CO}_{2}}=20^{\circ} \mathrm{C}, \rho_{\mathrm{CO}_{2}}=0.0018 \mathrm{~g} / \mathrm{mL}\right)$. The extracts were collected in glass bottles. The yield was determined gravimetrically and calculated using the following equation:

Yield of oil (g/100 g seed powder $)=$

$$
\frac{\text { Weight of extracted oil }(g)}{\text { Weight of E. ulmoides seed powder }(g)} \times 100
$$

\subsection{Experimental design}

RSM based on a central composite design (CCD) was employed in this study. The extraction efficiency of $\mathrm{SC}-\mathrm{CO}_{2}$ relied on the pressure, temperature, extraction time, flow

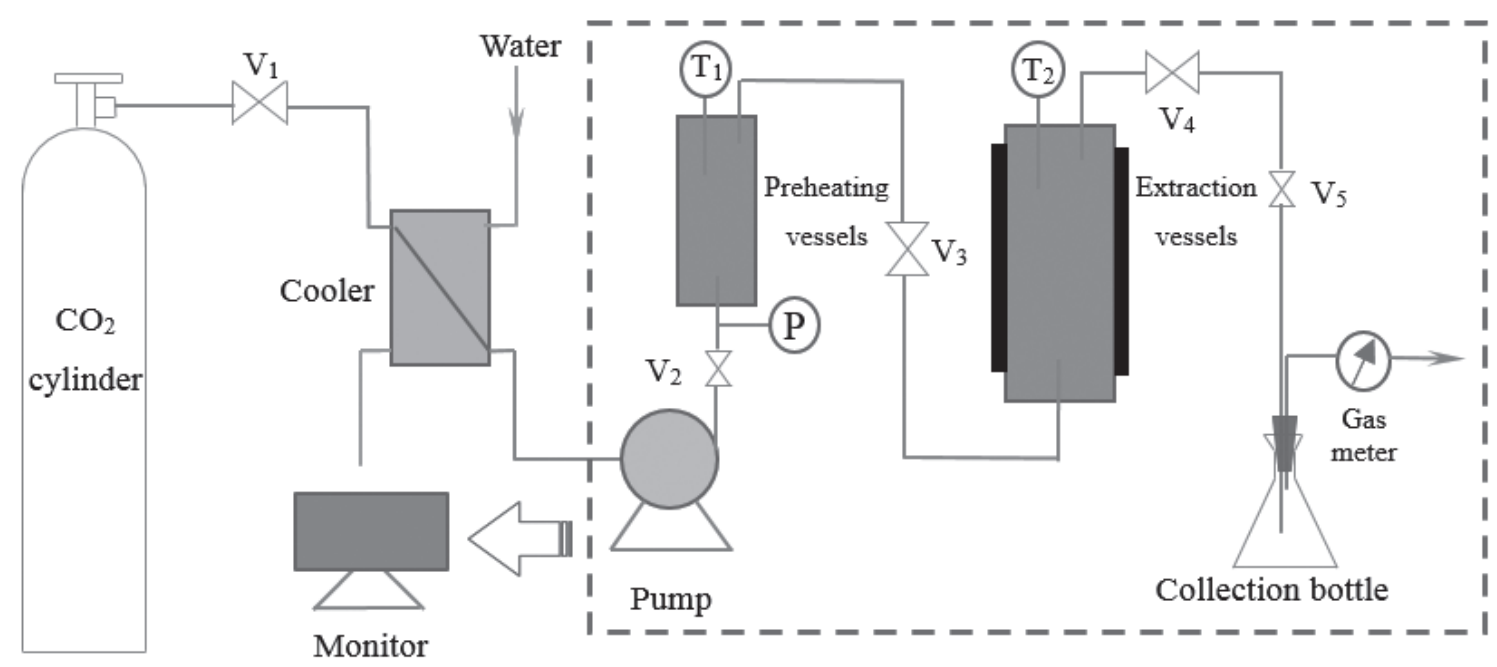

Fig. 1 Schematic diagram of supercritical carbon dioxide extraction equipment.

Table 1 Uncoded and coded levels of independent variables used in the RSM design.

\begin{tabular}{lcrrrrr}
\hline \multirow{2}{*}{ Independent variables } & Symbols & \multicolumn{5}{c}{ Levels } \\
\cline { 3 - 7 } & & -2 & -1 & 0 & 1 & \multicolumn{1}{c}{2} \\
\hline Pressure $(\mathrm{MPa})$ & $X_{1}$ & 20 & 25 & 30 & 35 & 40 \\
Temperature $\left({ }^{\circ} \mathrm{C}\right)$ & $X_{2}$ & 30 & 35 & 40 & 45 & 50 \\
Extraction time $(\mathrm{min})$ & $X_{3}$ & 30 & 60 & 90 & 120 & 150 \\
$\mathrm{CO}_{2}$ flow rate $(\mathrm{SL} / \mathrm{min})$ & $X_{4}$ & 1 & 2 & 3 & 4 & 5 \\
\hline
\end{tabular}


rate of $\mathrm{CO}_{2}$, as well as moisture content and particle size of samples $^{12)}$. Based on preliminary experiments, the studied variables and their ranges were selected and listed in Table 1. The experimental design consisted of 30 experiment runs, six replicate runs at the center point $(0,0,0,0)$ of the design were performed to allow the estimation of the pure error. All experiments were carried out three times in a randomized order and average experimental values were reported. The central composite design and experimental results are shown in Table 2.

A second-order polynomial regression model was used for predicting responses of $Y$ (oil yield). The generalized form of that regression model is shown as follows:

$$
Y=\beta_{0}+\sum_{i=1}^{4} \beta_{i} X_{i}+\sum_{i=2}^{4} \beta_{i i} X_{i}^{2}+\sum_{i=1}^{3} \sum_{j=i+1}^{4} \beta_{i j} X_{i} X_{j}
$$

where $Y$ is the response, $X_{i}$ and $X_{j}$ are variables, $\beta_{0}$ is a constant and $\beta_{i}, \beta_{i i}$ and $\beta_{i j}$ are the linear, quadratic and interactive coefficients, respectively. Statistical analysis of the experimental data was performed using the software of Design Expert(Version 8.0.7.1, Stat-Ease Inc., Minneapolis, USA).

Table 2 Central composite design and data of $\mathrm{SC}-\mathrm{CO}_{2}$ extraction $(\mathrm{n}=3)$.

\begin{tabular}{|c|c|c|c|c|c|c|}
\hline \multirow{2}{*}{$\begin{array}{c}\text { Run } \\
\text { number }\end{array}$} & \multirow{2}{*}{$\begin{array}{c}X_{1} \text { : Pressure } \\
(\mathrm{MPa})\end{array}$} & \multirow{2}{*}{$\begin{array}{c}X_{2}: \\
\text { Temperature } \\
\left({ }^{\circ} \mathrm{C}\right)\end{array}$} & \multirow{2}{*}{$\frac{X_{3}: \text { Time }}{(\min )}$} & \multirow{2}{*}{$\frac{X_{4} \text { : Flow rate }}{(\mathrm{SL} / \mathrm{min})}$} & \multicolumn{2}{|c|}{ Oil yield (g/100 g seed) } \\
\hline & & & & & Experimental & Predicted \\
\hline 1 & 25 & 35 & 60 & 2 & 17.81 & 18.23 \\
\hline 2 & 35 & 35 & 60 & 2 & 25.05 & 24.52 \\
\hline 3 & 25 & 45 & 60 & 2 & 22.31 & 22.56 \\
\hline 4 & 35 & 45 & 60 & 2 & 23.91 & 24.30 \\
\hline 5 & 25 & 35 & 120 & 2 & 20.79 & 19.98 \\
\hline 6 & 35 & 35 & 120 & 2 & 26.86 & 26.61 \\
\hline 7 & 25 & 45 & 120 & 2 & 25.79 & 25.97 \\
\hline 8 & 35 & 45 & 120 & 2 & 27.80 & 28.05 \\
\hline 9 & 25 & 35 & 60 & 4 & 22.81 & 22.21 \\
\hline 10 & 35 & 35 & 60 & 4 & 26.63 & 26.77 \\
\hline 11 & 25 & 45 & 60 & 4 & 22.02 & 22.59 \\
\hline 12 & 35 & 45 & 60 & 4 & 22.13 & 22.59 \\
\hline 13 & 25 & 35 & 120 & 4 & 22.91 & 22.84 \\
\hline 14 & 35 & 35 & 120 & 4 & 28.33 & 27.73 \\
\hline 15 & 25 & 45 & 120 & 4 & 24.71 & 24.89 \\
\hline 16 & 35 & 45 & 120 & 4 & 25.32 & 25.22 \\
\hline 17 & 20 & 40 & 90 & 3 & 21.07 & 21.00 \\
\hline 18 & 40 & 40 & 90 & 3 & 27.54 & 27.64 \\
\hline 19 & 30 & 30 & 90 & 3 & 20.32 & 21.46 \\
\hline 20 & 30 & 50 & 90 & 3 & 24.39 & 23.28 \\
\hline 21 & 30 & 40 & 30 & 3 & 23.48 & 22.92 \\
\hline 22 & 30 & 40 & 150 & 3 & 26.70 & 27.30 \\
\hline 23 & 30 & 40 & 90 & 1 & 23.85 & 23.89 \\
\hline 24 & 30 & 40 & 90 & 5 & 25.05 & 25.04 \\
\hline 25 & 30 & 40 & 90 & 3 & 28.16 & 27.28 \\
\hline 26 & 30 & 40 & 90 & 3 & 27.59 & 27.28 \\
\hline 27 & 30 & 40 & 90 & 3 & 26.05 & 27.28 \\
\hline 28 & 30 & 40 & 90 & 3 & 27.24 & 27.28 \\
\hline 29 & 30 & 40 & 90 & 3 & 26.27 & 27.28 \\
\hline 30 & 30 & 40 & 90 & 3 & 28.37 & 27.28 \\
\hline
\end{tabular}




\subsection{Analysis of fatty acid composition}

Fatty acid methyl esters (FAMEs) were prepared according to the method described by Zhang et $a l .{ }^{16)}$.

GC analysis was performed on an Agilent 7890B Gas Chromatograph (Agilent Technologies, USA), equipped with a flame ionization detector and a HP-Innowax capillary column $(30 \mathrm{~m} \times 0.32 \mathrm{~mm}$ i.d., film thickness $0.25 \mu \mathrm{m}$, Agilent Technologies, USA). The column was kept at $140^{\circ} \mathrm{C}$ for $5 \mathrm{~min}$, and then raised to $240^{\circ} \mathrm{C}$ at $4{ }^{\circ} \mathrm{C} / \mathrm{min}$. The injector and detector temperatures were $240^{\circ} \mathrm{C}$ and $280^{\circ} \mathrm{C}$, respectively. Nitrogen was used as the carried gas at $1.0 \mathrm{~mL} / \mathrm{min}$ and the split ratio was 1:50. The fatty acids peaks were identified by comparison of retention times with those of standards. Fatty acid methyl esters were quantified as percentages of the total methyl ester peak areas.

\subsection{Analysis of vitamin E}

Half a gram of $E$. ulmoides seed oil was dissolved in 10 $\mathrm{mL}$ of n-hexane, then filtered using a $0.45 \mu \mathrm{m}$ PTFE filter for HPLC analysis. The analysis of tocopherols and tocotrienols were performed using a Waters e2695 HPLC system (Waters Corporation, Milford, USA) equipped with a Waters 2475 fluorescence detector(Waters Corporation, Milford, USA) and an Elite $\mathrm{NH}_{2}$ column $(250 \mathrm{~mm} \times 4.6 \mathrm{~mm} \times 5 \mu \mathrm{m}$, Dalian Elite Analytical Co., Ltd, Dalian, China). The column temperature was $40^{\circ} \mathrm{C}$. The mobile phase was isopropanol: hexane $(1: 99, \mathrm{v} / \mathrm{v})$, flow rate $0.8 \mathrm{~mL} / \mathrm{min}$. The excitation wavelength was $298 \mathrm{~nm}$ and the emission wavelength was $325 \mathrm{~nm}$. The tocopherols and tocotrienols were identified by comparing their retention times with authentic standards and quantified based on the peak areas compared with the external standards.

\subsection{Physicochemical analysis}

AOCS Official Methods ${ }^{17)}$ were used to determine the acid value (Cd 3d-63), peroxide value (Cd 8-53), iodine value (Cd 1-25) and saponification value (Cd 3-25) of $E$. ulmoides seed oil. The color was determined by visual check. The specific gravity and refractive index were determined at a room temperature of $25^{\circ} \mathrm{C}$ using a specific gravity bottle and an Abbe refractometer, respectively. All experiments were repeated three times, and the average values were reported.

\section{Results and discussion \\ 3.1 Fitting the model}

A second-order polynomial equation was fitted to the experimental data to develop a mathematical model, which will assist in predicting the extraction efficiency. The developed regression model obtained in terms of coded levels is given below:

$$
\begin{aligned}
Y= & 27.28+1.66 X_{1}+0.46 X_{2}+1.09 X_{3}+0.29 X_{4}-1.14 X_{1} X_{2} \\
& +0.08 X_{1} X_{3}-0.44 X_{1} X_{4}+0.42 X_{2} X_{3}-0.99 X_{2} X_{4}- \\
& 0.28 X_{3} X_{4}-0.74 X_{1}^{2}-1.23 X_{2}^{2}-0.54 X_{3}^{2}-0.70 X_{4}^{2}
\end{aligned}
$$

Higher model $F$-value (20.52) and lower $p$-value $(p<$ $0.0001)$ demonstrated the significance of the developed model and implied that the model was suitable for the present experimental data. Meanwhile, "lack of fit" of this model was insignificant with the $p$-value being 0.7340 . The coefficient of determination $\left(\mathrm{R}^{2}\right)$ and adjusted coefficient of determination (Adj $R^{2}$ )were 0.9504 and 0.9041 , respectively, which indicated that the accuracy and general availability of the polynomial model are adequate ${ }^{12)}$. In addition, lower value of coefficient of variation (C.V. $=3.40 \%)$ displayed the high degree of precision and good reliability of the conducted experiments ${ }^{8}$. The adequate precision measures the signal to noise ratio and the ratio greater than 4 is desirable. In this study, the adequate precision was 16.52 which indicates an adequate signal and therefore the model can be used to navigate the design space.

The significance of each coefficient was also determined by the $\mathrm{F}$-value and $p$-value. A value of $p<0.05$ indicates that the equation term was significant. In this case, $X_{1}, X_{2}$, $X_{3}, X_{1} X_{2}, X_{2} X_{4}, X_{1}^{2}, X_{2}^{2}, X_{3}^{2}$ and $X_{4}^{2}$ were all significant equation terms. Besides, the larger magnitude of $\mathrm{F}$-values and the smaller $p$-values mean a higher significance of the corresponding coefficient ${ }^{18)}$. The influence on the oil yield decreased in the order of pressure $>$ extraction time $>$ temperature $>\mathrm{CO}_{2}$ flow rate.

The predicted value of $E$. ulmoides seed oil yield was calculated using the regression equation(Eq. 3) and compared with the experimental values in Table 2. The high linear correlation coefficient $(\mathrm{R}=0.9748)$ between predicted and experimental values indicated the model was suitable. The residuals normal probability plot indicates that the residuals (difference between actual and predicted values) follow a normal distribution and form an approximately straight line.

\subsection{Response surface analysis}

The best way of expressing the effect of any parameter on the yield within the experimental range was to generate response surface plots of the model ${ }^{19)}$. Three-dimensional profiles of the regression model were used to depict the interactive effect of process variables for the oil yield (Figs. 2a-f).

3.2.1 Effect of extraction pressure

Pressure is one of the most important factors which effect the extraction efficiency of oil in $\mathrm{SC}_{-} \mathrm{CO}_{2}$ extraction. Figures $2 \mathrm{a}, \mathrm{b}$ and $\mathrm{c}$ show the interactive effect of pressure with each of three other factors on the oil yield. From the figures, it was observed that extraction pressure is more important than any other variables. The oil yield increased significantly with increasing pressure, particularly at lower 

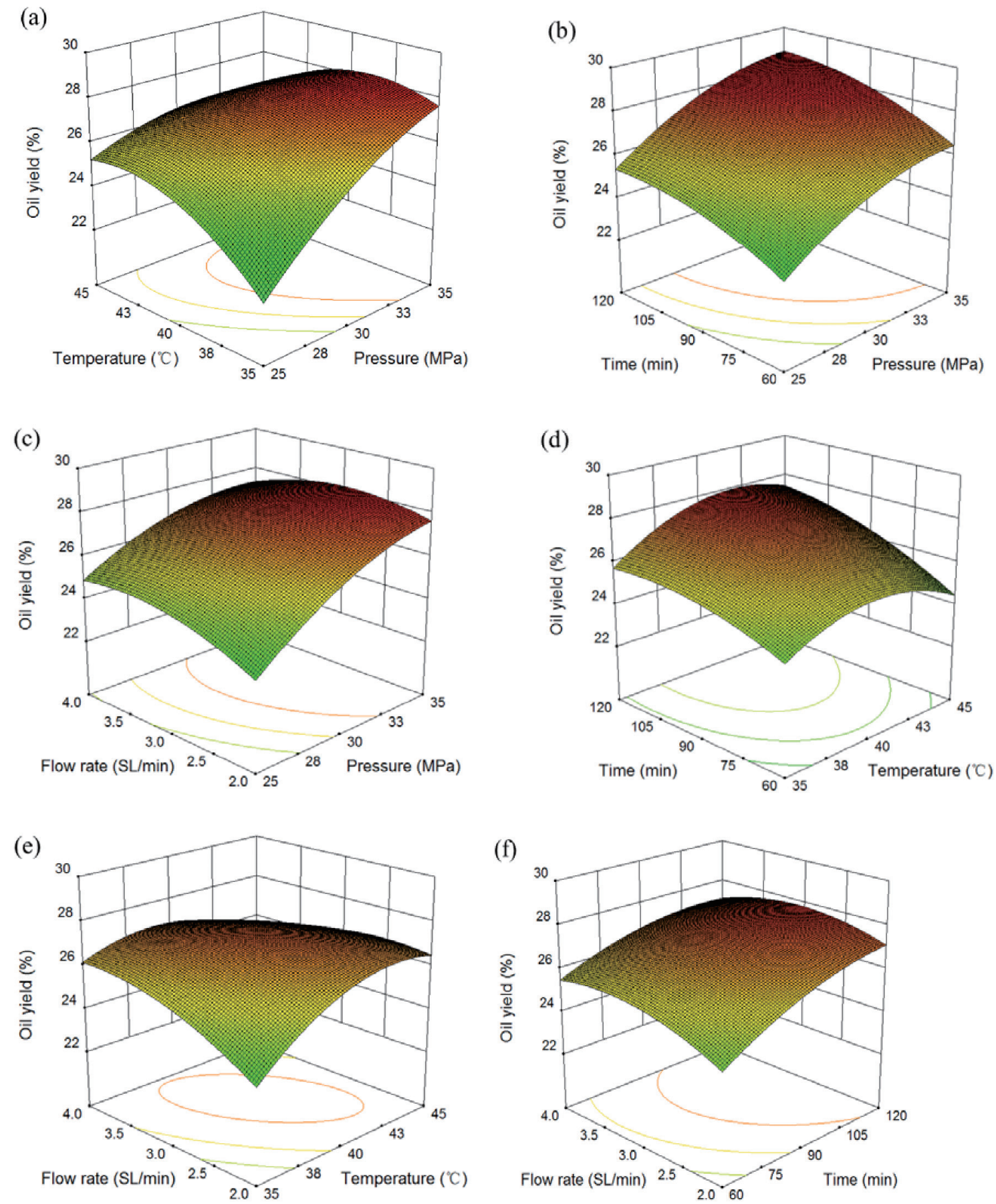

Fig. 2 Response surface plots showing the interactive effect of process variables on oil yield.

pressure. This is most likely due to that the rise of pressure results in an increase in the density, which in turn improved the solubility of $E$. ulmoides seed oil in $\mathrm{SC}-\mathrm{CO}_{2}$. However, once the pressure reached high levels, the oil yield increased slowly, even decreased. The likely reason was that the highly compressed $\mathrm{CO}_{2}$ at high-pressure levels facilitates solute-solvent repulsion ${ }^{20)}$. These results are in agreement with the $\mathrm{SC}-\mathrm{CO}_{2}$ extraction of silkworm pupal oil $^{12)}$, Mucuna seed oil ${ }^{21)}$ and almond oil ${ }^{22)}$. Moreover, in view of safety and economic reasons, high pressure is not always recommended for $\mathrm{SC}-\mathrm{CO}_{2}$ extraction.

3.2.2 Effect of extraction temperature

Figures $2 \mathrm{a}, \mathrm{d}$ and e show the interaction of temperature with pressure, extraction time and $\mathrm{CO}_{2}$ flow rate, respectively. It can be seen that the oil yield increased with the increase of temperature in low temperature zone. However, 
at higher temperature levels (above $40^{\circ} \mathrm{C}$ ), the oil yield decreased with the further increasing of temperature. This is most likely due to the counter effect of temperature on the oil yield. On the one hand, temperature rise increased mass transfer speed and the vapor pressure of solute, which accelerated desorption of the oil from the seed matrix and elevated the solubility of oil in $\mathrm{SC}_{-} \mathrm{CO}_{2}{ }^{19)}$. However, on the other hand, increasing temperature reduced the density of $\mathrm{SC}-\mathrm{CO}_{2}$, leading to the reduction in solvent power to dissolve the solute ${ }^{21)}$, which restrict the increase of oil yield. Therefore, the oil yield will tend to increase, remain constant, or decrease with increasing of temperature, which depend on whether the mass transfer speed and solute vapor pressure or the solvent density is predominant ${ }^{11,14)}$. Similar phenomena were also found in the $\mathrm{SC}_{-} \mathrm{CO}_{2}$ extraction of other vegetable oils ${ }^{20,22)}$.

3.2.3 Effect of extraction time

Figures $2 b, d$ and $f$ show the interaction of extraction time with pressure, temperature and $\mathrm{CO}_{2}$ flow rate, respectively. Form the figures, it was observed that the oil yield increased dramatically with increasing of time and then leveled off after $110 \mathrm{~min}$. Higher amount of oil recovery at initial extraction time may be due to the more oil contained in the surface of the samples. With the reducing of oil in the surface, $\mathrm{SC}-\mathrm{CO}_{2}$ had to spent more time to penetrate into the cell matrix, dissolve the oil and subsequently diffuse out from the materials. A longer extraction time had a positive effect on the oil yield. However, as shown in the figures, further increase in the extraction time from $110 \mathrm{~min}$ resulted in little change in the oil yield. Therefore, it is reasonable for $E$. ulmoides seed oil that the extraction time of $\mathrm{SC}-\mathrm{CO}_{2}$ extraction was about $110 \mathrm{~min}$.

\subsubsection{Effect of $\mathrm{CO}_{2}$ flow rate}

Figures $2 \mathrm{c}$, e and $\mathrm{f}$ show the interaction of $\mathrm{CO}_{2}$ flow rate with pressure, temperature and extraction time, respectively. As shown in the figures, the oil yield can be adjusted by changing the flow rate of $\mathrm{CO}_{2}$ at the beginning of extraction period (constant extraction rate period). It can be explained by decrease of mass transfer resistance and increase in convection when high flow rate of solvent is used $^{23)}$. However, there is no significant difference in oil yield when the flow rate of $\mathrm{CO}_{2}$ was beyond to $3.5 \mathrm{SL} / \mathrm{min}$. This may be due to that the extraction was controlled mainly by diffusion of oil from the cell matrix, thus increasing the flow rat could not manipulate the rate of diffusion ${ }^{8}$.

\subsection{Optimization of extraction condition}

Solving the regression equation (Eq. 3) with Software of Design Expert, the optimum levels of the test factors were extraction pressure at $36.89 \mathrm{MPa}$, extraction temperature at $39.49^{\circ} \mathrm{C}$, extraction time at $125.13 \mathrm{~min}$, and $\mathrm{CO}_{2}$ flow rate at $2.62 \mathrm{SL} / \mathrm{min}$. The maximum predicted oil yield was $28.99 \mathrm{~g} / 100 \mathrm{~g}$ seed. However, considering the operability in actual production, the optimal condition can be modified as follows: extraction pressure at $37 \mathrm{MPa}$, extraction temperature at $40^{\circ} \mathrm{C}$, extraction time at $125 \mathrm{~min}$, and $\mathrm{CO}_{2}$ flow rate at $2.6 \mathrm{SL} / \mathrm{min}$. Under this condition, the mean value of practical oil yield was $28.75 \mathrm{~g} / 100 \mathrm{~g}$ seed. The good correlation between predicted value and actual value confirmed that the response model was adequate to reflect the expected optimization. In addition, the oil yield of $\mathrm{SC}_{-} \mathrm{CO}_{2}$ extraction at optimal condition were close to the total oil content (32.14 g/100 g seed) measured by Soxhlet method, which indicated $\mathrm{SC}-\mathrm{CO}_{2}$ was of high extraction efficiency for extracting oil from E. ulmoides seed.

\subsection{Fatty acid composition}

The fatty acid composition of $E$. ulmoides seed oil were determined using GC and listed in Table 3. It can be observed that five major fatty acids were present in the $E$. ulmoides seed oil, which were linolenic (about $61 \%$ ), oleic (about 17\%), linoleic (about 12\%), palmitic (about 6.5\%) and stearic (about $2 \%$ ). This result was generally consistent with those reported by Zhang et $a l .{ }^{24)}$. It was worth noting that the fatty acid composition of $E$. ulmoides seed oil was similar with that of flaxseed oil ${ }^{25)}$ and perilla oil ${ }^{26)}$ as shown in Table 3. It can be inferred that E. ulmoides seed oil can be used as an alternative to flaxseed oil and perilla oil, and may have the same function and efficacy in preventing disorder such as cardiovascular disease, atherosclerosis, diabetes, cancer, and so on. But, the difference of these oils in triacylglycerol distribution need a further research.

\subsection{Vitamin E composition}

Vitamin $\mathrm{E}$ is a natural antioxidant that can stabilize vegetable oils. Vitamin E can be divided into two groups of tocopherols (TP) and tocotrienols (TT). Each of groups have four isomers, designated as $\alpha-, \beta-, \gamma_{-}, \delta$-, which differ in number and position of methyl groups in the chromanol ring. As shown in Fig. 3, because of the difficulty involved in distinguishing the $\beta$ - and $\gamma$-isomers of tocotrienols, the sum of these two isomers is shown throughout as $(\beta+\gamma)$ tocotrienols. From Table 4, $\gamma$ - and $\delta$-tocopherol were the main isomers of vitamin $\mathrm{E}$ in $E$. ulmoides seed oil, respectively, accounting for $70.87 \%$ and $24.81 \%$. The total vitamin E content in E. ulmoides seed oil was 190.72 $\mathrm{mg} / 100 \mathrm{~g}$, which was higher than that of soybean oil(118.8 $\mathrm{mg} / 100 \mathrm{~g})$, sunflower oil (54.7 mg/100 g), and rapeseed oil $(79.7 \mathrm{mg} / 100 \mathrm{~g})$ as reported by Nagy et $a l .{ }^{27)}$. In addition, the concentration of vitamin $\mathrm{E}$ in oils was influenced by extraction pressure, temperature, solvent and method. Trentini et al. reported that the oil extracted with subcritical propane contained more vitamin $\mathrm{E}$ than that of soxhlet extraction $^{28)}$. It was suggested that higher temperatures and lower pressures will lead to higher levels of vitamin $\mathrm{E}$ in the oils extracted with supercritical fluid as reported by Santos $e a{ }^{29)}$. Some studies have reported that vitamin $\mathrm{E}$ 
SC-CO Extraction of E. ulmoides Seed Oil and Quality Evalution of its Oil

Table 3 Fatty acid composition of E. ulmoides seed oil.

\begin{tabular}{lccc}
\hline \multicolumn{1}{c}{ Fatty acids } & E. ulmoides seed oil & Flaxseed oil $^{\mathrm{a}}$ & Perilla oil $^{\mathrm{b}}$ \\
\hline Saturated & & & \\
C8:0 & - & - & 0.68 \\
C16:0 & $6.68 \pm 0.11$ & 5.22 & 4.11 \\
C18:0 & $2.40 \pm 0.05$ & 4.12 & 1.87 \\
C20:0 & $0.49 \pm 0.08$ & 0.20 & 0.18 \\
C22:0 & $0.30 \pm 0.01$ & 0.15 & 0.08 \\
C24:0 & $0.19 \pm 0.00$ & 0.13 & 0.07 \\
Monounsaturated & & & \\
C16:1 & $0.09 \pm 0.00$ & 0.00 & 0.11 \\
C18:1 & $17.32 \pm 0.23$ & 18.30 & 16.65 \\
C20:1 & $0.06 \pm 0.01$ & 0.00 & - \\
Polyunsaturated & & & \\
C18:2 & $12.06 \pm 0.04$ & 15.60 & 14.32 \\
C18:3 & $60.51 \pm 0.35$ & 56.28 & 61.93 \\
SFA & 10.06 & 9.82 & 6.99 \\
MUFA & 17.47 & 18.30 & 16.76 \\
PUFA & 72.57 & 71.88 & 76.25 \\
PUFA/SFA & 7.21 & 7.32 & 10.91 \\
\hline
\end{tabular}

${ }^{a}$ The data was reported by Khattab and Zeitoun ${ }^{25)}$.

${ }^{\mathrm{b}}$ The data was reported by Li et al. ${ }^{26)}$.

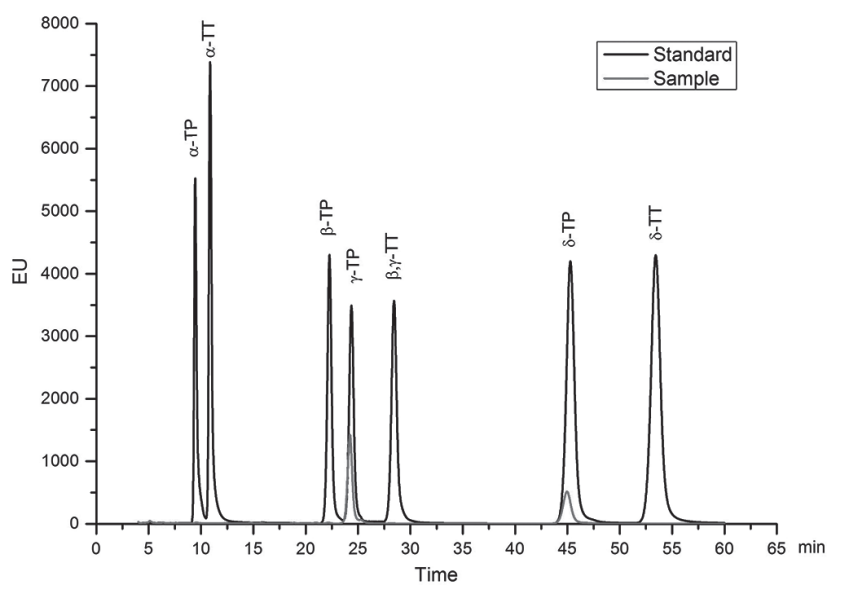

Fig. 3 HPLC Chromatogram of Vitamin E of E. ulmoides seed oil.

has the ability to prevent chronic diseases, cardiovascular diseases, atherosclerosis and cancer ${ }^{30)}$. Therefore, it is inferred that E. ulmoides seed oil can be developed as a kind of functional healthy oil.

\subsection{Physicochemical properties}

The physical properties (refractive index and color) and chemical properties (acid value, iodine value, peroxide value and saponification value) of $E$. ulmoides seed oil ex- tracted at optimum conditions of $\mathrm{SC}-\mathrm{CO}_{2}$ extraction were determined. At room temperature, E. ulmoides seed oil was primrose yellow and had a specific gravity of $0.921 \pm$ 0.040 . The high refractive index $(1.481 \pm 0.003)$ and iodine value $\left(194.25 \pm 1.02 \mathrm{~g} \mathrm{I}_{2} / 100 \mathrm{~g}\right)$ indicated that $E$. ulmoides seed oil possess a high content of unsaturated fatty acid. The low acid value $(0.91 \pm 0.04 \mathrm{mg} \mathrm{KOH} / \mathrm{g})$ and peroxide value $\left(4.43 \pm 0.18 \mathrm{meq} \mathrm{O}_{2} / \mathrm{kg}\right.$ oil) proved that the oil has high antioxidant capacity and a long storage period ${ }^{26)}$. The high saponification value $(186.47 \pm 0.47 \mathrm{mg} \mathrm{KOH} / \mathrm{g})$ indicated that E. ulmoides seed oil have a high content of low molecular weight triacylglycerol. In summary, both physical and chemical properties of the oil demonstrated that $E$. ulmoides seed oil is a promising source of edible oil.

\section{Conclusion}

In this study, RSM was applied to optimize $\mathrm{SC}_{-} \mathrm{CO}_{2}$ extraction parameters to obtain the highest yield of $E$. ulmoides seed oil. Results revealed that pressure, temperature and extraction time were significant, but $\mathrm{CO}_{2}$ flow rate was not significant. The optimal conditions within the experimental ranges could be obtained at a pressure of 37 $\mathrm{MPa}$, extraction temperature of $40^{\circ} \mathrm{C}$, extraction time of $125 \mathrm{~min}$, and $\mathrm{CO}_{2}$ flow rate of $2.6 \mathrm{SL} / \mathrm{min}$. GC analysis indi- 
Table 4 Vitamin E composition of E. ulmoides seed oil.

\begin{tabular}{lcccc}
\hline \multicolumn{1}{c}{ Vitamin E isomer } & E. ulmoides seed oil & Soybean oil $^{\mathrm{a}}$ & Sunflower oil $^{\mathrm{a}}$ & Rapeseed oil $^{\mathrm{a}}$ \\
\hline$\alpha$-Tocopherol & $2.66 \pm 0.49$ & $11.7 \pm 4.0$ & $46.5 \pm 9.6$ & $27.7 \pm 7.7$ \\
$\beta$-Tocopherol & $2.85 \pm 0.24$ & $1.7 \pm 0.7$ & $2.5 \pm 0.8$ & $0.4 \pm 0.3$ \\
$\gamma$-Tocopherol & $135.174 \pm 2.06$ & $73.3 \pm 17.0$ & $3.8 \pm 6.5$ & $50.0 \pm 15.4$ \\
$\delta$-Tocopherol & $47.32 \pm 0.39$ & $31.7 \pm 8.3$ & $1.1 \pm 2.4$ & $1.2 \pm 0.5$ \\
$\alpha$-Tocotrienol & $1.22 \pm 0.42$ & $0.1 \pm 0.2$ & $0.2 \pm 0.2$ & $0.1 \pm 0.3$ \\
$(\beta+\gamma)$-Tocotrienol & $0.28 \pm 0.25$ & $0.2 \pm 0.4$ & $0.5 \pm 0.4$ & $0.3 \pm 0.9$ \\
$\delta$-Tocotrienol & $1.51 \pm 0.32$ & $0.1 \pm 0.1$ & $0.1 \pm 0.1$ & $0.0 \pm 0.2$ \\
$\sum \mathrm{TP}$ mg/100 g & 188.00 & 118.40 & 53.96 & 79.30 \\
$\sum \mathrm{TT}$ mg/100 g & 2.73 & 0.4 & 0.8 & 0.4 \\
$\sum \mathrm{V}_{\mathrm{E}} \mathrm{mg} / 100 \mathrm{~g}$ & 190.72 & 118.8 & 54.7 & 79.7 \\
\hline
\end{tabular}

${ }^{\mathrm{a}}$ The data was reported by Nagy et al. ${ }^{27)}$.

cated that main fatty acids in E. ulmoides seed oil were linolenic, oleic, linoleic, palmitic and stearic, which was similar with that of flaxseed oil and perilla oil. But the difference of these oils in triacylglycerol distribution need a further research. E. ulmoides seed oil was rich in vitamin $\mathrm{E}(190.72 \mathrm{mg} / 100 \mathrm{~g})$, and the predominant vitamin $\mathrm{E}$ isomers were $\gamma$ - tocopherol and $\delta$ - tocopherol. More content of linolenic acid and vitamin E suggested E. ulmoides seed oil was prone to oxidation and degradation at high temperature. The good physicochemical properties of extracted oil proven that $\mathrm{SC}-\mathrm{CO}_{2}$ extraction is suitable for E. ulmoides seed oil.

\section{References}

1) Zhu, M.Q.; Wen, J.L.; Zhu, Y.H.; Su, Y.Q.; Sun, R.C. Isolation and analysis of four constituents from barks and leaves of Eucommia ulmoides Oliver by a multi-step process. Ind. Crop. Prod. 83, 124-132(2016).

2) Hong, Y.K.; Liu, W.J.; Li, T.; She, S.Y. Optimization of extraction of Eucommia ulmoides polysaccharides by response surface methodology. Carbohydr. Polym. 92, 1761-1766 (2013).

3) Li, H.; Chen, B.; Yao, S.H. Application of ultrasonic technique for extracting chlorogenic acid from $E u$ commia ulmodies Oliv. (E. ulmodies). Ultrason. Sonochem. 12, 295-300 (2005).

4) Xu, J.K.; Li, M.F.; Sun, R.C. Identifying the impact of ultrasound-assisted extraction on polysaccharides and natural antioxidants from Eucommia ulmoides Oliver. Process Biochem. 50, 473-481(2015).

5) Feng, H.B.; Fan, J.; Song, Z.H.; Du, X.G.; Chen, Y.; Wang, J.S.; Song, G.D.. Characterization and immunoenhancement activities of Eucommia ulmoides polysaccharides. Carbohydr. Polym. 136, 803-811 (2016).
6) He, X.R.; Wang, J.H.; Li, M.X.; Hao, D.J.; Yang, Y.; Zhang, C.L.; He, R.; Tao. R. Eucommia ulmoides Oliv.: Ethnopharmacology, phytochemistry and pharmacology of an important traditional Chinese medicine. J. Ethnopharmacol. 151, 78-92 (2014).

7) Bhattacharjee, P.; Singhal, R.S.; Tiwari, S.R. Supercritical carbon dioxide extraction of cottonseed oil. $J$. Food Eng. 79, 892-898 (2007).

8) Maran, J.P.; Priya, B. Supercritical fluid extraction of oil from muskmelon (Cucumis melo) seeds. J. Taiwan Inst. Chem. E. 47, 71-78(2015).

9) Belayneh, H.D.; Wehling, R.L.; Cahoon, E.; Ciftci, O.N. Extraction of omega-3-rich oil from Camelina sativa seed using supercritical carbon dioxide. J. Supercrit. Fluids 104, 153-159 (2015).

10) Eller, F.J.; Cermak, S.C.; Taylor, S.L. Supercritical carbon dioxide extraction of cuphea seed oil. Ind. Crop. Prod. 33, 554-557 (2011).

11) Thana, P.; Machmudah, S.; Goto, M.; Sasaki, M.; Pavasant, P.; Shotipruk, A. Response surface methodology to supercritical carbon dioxide extraction of astaxanthin from haematococcus pluvialis. Bioresour. Technol. 99, 3110-3115 (2008).

12) Wei, Z.J.; Liao, A.M.; Zhang, H.X.; Liu, J.; Jiang, S.T. Optimization of supercritical carbon dioxide extraction of silkworm pupal oil applying the response surface methodology. Bioresour. Technol. 100, 42144219 (2009).

13) Povilaitis, D.; Venskutonis, P.R. Optimization of supercritical carbon dioxide extraction of rye bran using response surface methodology and evaluation of extract properties. J. Supercrit. Fluids 100, 194-200 (2015).

14) Rai, A.; Mohanty, B.; Bhargava, R. Supercritical extraction of sunflower oil: a central composite design for extraction variables. Food Chem. 192, 647-659 (2016).

15) Kraujalis, P.; Venskutonis, P.R. Optimisation of super- 
critical carbon dioxide extraction of amaranth seeds by response surface methodology and characterization of extracts isolated from different plant cultivars. $J$. Supercrit. Fluids 73, 80-86(2013).

16) Zhang, Z.S.; Wang, L.J.; Li, D.; Jiao, S.S.; Chen, X.D.; Mao, Z.H. Ultrasound-assisted extraction of oil from flaxseed. Sep. Purif. Technol. 62, 192-198(2008).

17) AOCS. Official methods and recommended practices of the American Oil Chemists' Society (5th ed.). AOCS Press, Champaign, USA(1997).

18) Zhao, S.; Zhang, D. Supercritical $\mathrm{CO}_{2}$ extraction of Eucalyptus leaves oil and comparison with Soxhlet extraction and hydro-distillation methods. Sep. Purif. Technol. 133, 443-451 (2014).

19) Porto, C.D.; Voinovich, D.; Decorti, D.; Natolino, A. Response surface optimization of hemp seed (Cannabis sativa L.) oil yield and oxidation stability by supercritical carbon dioxide extraction. J. Supercrit. Fluids 68, 45-51 (2012).

20) Ni, Q.X.; Gao, Q.X.; Yu, W.W.; Liu, X.Q.; Xu, G.Z.; Zhang, Y.Z. Supercritical carbon dioxide extraction of oils from two torreya grandis varieties seeds and their physicochemical and antioxidant properties. $L W T$ Food Sci. Technol. 60, 1226-1234(2015).

21) Garcia, V.A.D.S.; Cabral, V.F.; Éverton, F.Z.; Silva, C.D.; Filho, L.C. Extraction of Mucuna seed oil using supercritical carbon dioxide to increase the concentration of L-Dopa in the defatted meal. J. Supercrit. Fluids 69, 75-81 (2012).

22) Zhang, Q.A.; Fan, X.H.; Zhang, Z.Q.; Zhang, B.S.; Zhang, Z.Q.; Jia, X.Y. Optimization of $\mathrm{SC}-\mathrm{CO}_{2}$ extraction of oil from almond pretreated with autoclaving. LWT - Food Sci. Technol. 42, 1530-1537 (2009).

23) Tai, H.P.; Kim, K.P.T. Supercritical carbon dioxide ex- traction of Gac oil. J. Supercrit. Fluids 95, 567-571 (2014).

24) Zhang, L.X.; Ji, X.Y.; Tan, B.B.; Liang, Y.Z.; Liang, N.N.; Wang, X.L.; Dai H. Identification of the composition of fatty acids in Eucommia ulmoides seed oil by fraction chain length and mass spectrometry. Food Chem. 121, 815-819 (2010).

25) Khattab, R.Y.; Zeitoun, M.A. Quality evaluation of flaxseed oil obtained by different extraction techniques. LWT - Food Sci. Technol. 53, 338-345(2013).

26) Li, H.Z.; Zhang, Z.J.; Hou, T.Y.; Li, X.J.; Chen, T. Optimization of ultrasound-assisted hexane extraction of perilla oil using response surface methodology. Ind. Crop. Prod.76, 18-24(2015).

27) Nagy, K.; Kerrihardb, A.L.; Beggio, M.; Craft, B.D.; Pegg, R.B. Modeling the impact of residual fat-soluble vitamin (FSV) contents on the oxidative stability of commercially refined vegetable oils. Food Res. Int. 84, 26-32 (2016).

28) Trentini, C.P.; Santos, K.A.; Silva, E.A.D.; Garcia, V.A.D.S.; Cardozo-Filho, L.; Silva, C.D. Oil extraction from macauba pulp using compressed propane. J. Supercrit. Fluids 126, 72-78(2017).

29) Santos, K.A.; Bariccatti, R.A.; Cardozo-Filho, L.; Schneider, R.; Palú, F.; Silva, C.D.; Silva, E.A.D. Extraction of crambe seed oil using subcritical propane: kinetics, characterization and modeling. J. Supercrit. Fluids 104, 54-61 (2015).

30) Karmowski, J.; Hintze, V.; Kschonsek, J.; Killenberg, M.; Bohm, V. Antioxidant activities of tocopherols/tocotrienols and lipophilic antioxidant capacity of wheat, vegetable oils, milk and milk cream by using photochemiluminescence. Food Chem. 175, 593-600 (2015). 